\title{
Evaluation of Digital Contents in Education: Examples of English and Health Education Applications in Japan
}

\author{
Minoru, MAEDA \\ Tokyo Gakugei University \\ 4-1-1, Nukuikitamachi, Koganei-shi, Tokyo \\ Japan, \\ edu@yalaw.net \\ Masato, FUJITA \\ Saitama Prefectural Iruma Koyo High School / Tokyo Gakugei University \\ 1-1-1, Koyodai, Iruma-shi, Saitama / 4-1-1, Nukuikitamachi, Koganei-shi, Tokyo \\ Japan, \\ b072918x@st.u-gakugei.ac.jp
}

\section{Evaluation of Digital Contents in Education}

In recent years, new school education using tablet personal computers has become an important issue in Japanese society. In the future, in schools all over the country, virtually all children will own tablets. Paper-based textbooks and teaching materials will be partially or completely transposed to digital form. The government of Japan is paying close attention to digital contents since they have the potential to introduce and rapidly expand interactive and active learning for students. In order to make this type of learning successful, proper evaluation of the quality of digital contents is necessary. We investigated how we can best apply to digital education the system that has been traditionally used to evaluate books and the extensive experience that school libraries have had with such evaluation. We found that a proper digital contents evaluation system can insure the effectiveness of learning activities for a specific learning unit and method of use.

Keywords: Digital Contents, Evaluation, Health Education 


\section{Introduction and Aim}

In June 2011, OECD (Organisation for Economic Co-operation and Development), an organization of advanced nations that deals with economic issues, released the results of a study examining the digital literacy of children. The focus of the OECD study was not on the teaching of computer skills, but rather on whether computers could be used effectively as a means for teaching subjects such as language, arithmetic, science, and social studies in the general school curriculum. In Japan, the percentage of students who were using a computer as a means of education in general curriculum subjects was found to be only $1 \%$. Of the 19 nations and regions that participated in the investigation, Japan ranked lowest.

In an attempt to explain this result, we considered two factors. First, in Japan, there are few titles of digital teaching materials that would be useful for school curriculum education. Indeed, although the worldwide information industry sells extensive application software that operates with smart phones or tablet computers, such application software is generally not helpful to education in Japanese schools. Second, Japanese teachers typically do not know how to utilize digital teaching materials effectively. Since there are few potentially useful titles available, use of such materials is unfamiliar to most teachers.

Clearly the two factors described here are related. As the number of appropriate titles increases, teachers will become more proficient in their use. Likewise, as teachers become more proficient in their use, the number of available titles will increase. To advance the process, the training of Japanese teachers in the digital age needs to improve.

Our research is aimed at evaluating the quality of digital teaching materials as a way of addressing both elements of the problem. This is especially important since education in Japan uses teaching materials based on textbook guidelines set by the government for all schools.

In Japan, sweeping revisions of the collection guidelines for school expenses, which are indicators of the contents of learning, are carried out once every ten years. Government guidelines for teaching describe the general contents of learning; the Japanese textbook exists as a manifestation of these contents. Under the current system, a private publishing company produces a book; the textbook screening system then determines whether the government guidelines for teaching are being properly followed. The board of education in each area then chooses from the list of approved textbooks. The cost of purchasing the book is absorbed in the governmental budget and the student is provided with the textbook without cost. The quality of education in Japan is directly related to the quality of the editing work done by publishing company professionals and the certificate examination process conducted by the 
government. The textbook is the driving force responsible for maintaining educational quality. As such, it is the focus of the educational resources of the country.

The situation changes significantly when textbooks are digitized. Such digitization, although still not widespread, is progressing in Japan. Digital textbooks that can be used by teachers with a projector or a media board are being released into the market. In the future, the availability of digital textbooks for use by children with a tablet computer is due to be expanded. Various digital teaching materials can be connected to a digital textbook using communication technology. All this is certain to create a learning environment in which children can explore on their own. In such a world, it is difficult to guarantee the educational quality that conventional textbooks have so far maintained. In a future marked by the boundless expansion of digital teaching materials, the establishment of a proper evaluation system will surely be needed.

\section{Aim}

In the school library, paper publications have been used for years. Traditional evaluation of paper publications in education has been extensively and routinely conducted. Now it is possible for teachers colleges to play a pacesetting role connecting teachers to the new technology. In this study, we examine the evaluation of the quality of digital teaching materials and link content evaluation to teacher training. We use as examples English education, which is our particular area of interest, and health education.

\section{Method}

In this study, we approached the evaluation of digital teaching materials from the domain of the school library. The school library has functioned historically as a place that offers extensive teaching-materials data. In a school library, selections made by a child or a teacher are very important. This is as true for digital teaching materials as it is for paper books. For the broad range of digital teaching materials, we want to be able to appropriately support the act of selection by both student and teacher. Of course, the paper books contained in the school library have been carefully chosen, and all the books of the world are certainly not present. A school library is learning environment in which only suitable books for school education are available. A school library approach similar to that used for paper books can be applied to digital teaching materials as well. Using as its foundation the system for recommending books in Japan, whereby a recommended book is determined by conference using certain criteria for selection, this research project was begun in 2012 to consider the creation of a system for recommending digital teaching materials. The short title of this project is "Deji Doku Hyouka Project." The project was organized in Tokyo Gakugei University and was completed in March, 2016. 
This project consisted of three sections: In the first section, we collected basic data for the evaluation of digital teaching materials. For example, we collected existing types of digital teaching materials and various kinds of textbooks. Moreover, for this part of our study, we visited schools and administered a questionnaire to school administrators or boards of education. In addition, we conducted an overseas investigation, deepening our understanding of relevant conditions in South Korea and Taiwan.

In the second section, we organized our human resources and discussed related issues with people in various positions. The project team were assigned roles. Members included: Minoru Maeda, project leader; Takeshi Fujii, Tokyo Gakugei University vice president; Namiko Tsuizaki, a visiting professor for this project: Namiko Tsuizaki, previously Director-General of the Executive Office of the Japan School Library Association; and Etsuko Tokuta, a former teacher, who participated as a researcher. In addition, a special committee composed of various school staff was formed. We also organized a special committee composed of various university personnel. School teachers working in various areas in Japan did the work of evaluating the digital teaching materials. We arranged to provide these teachers with the materials and asked them to try using them in their classes. Their opinions of the materials were collected by the project team and discussed by the project's assessment committee, which was composed of a university faculty member and teachers from a school neighboring Tokyo Gakugei University. To provide for a broad discussion of issues related to this research, a national forum was also held each year.

In the third section of the project, a trial relating both evaluation and teacher training was conducted. After creating appropriate criteria, we evaluated digital teaching materials experimentally. A study session for teachers, students, companies, teacher librarians, and school librarians was held every month. At these study sessions, we discussed the results of our daily work. Throughout the process, we continually sought to improve the interaction of the evaluation activities and our study session activity. "A List of Contents Useful for Teaching" was published, and both paper and digital examples of items on the list were introduced. In addition, we published a leaflet entitled, "Considering the Teaching Process of the Future."

Based on our progress, we held a committee debate at the university at the end of each fiscal year. At the conclusion of our four-year research period, we held a debriefing session in which a number of people from outside the university participated.

The Japanese government provided a subsidy for the project. The research described here also benefited from three research grants: a Scientific Research Grant, awarded in fiscal year 2007 (Basic Research (C) 19500204); an Important Research Grant, awarded by Tokyo Gakugei University in fiscal year 2009; and a Scientific Research Grant awarded in fiscal year 
2010 (Basic Research (C) topic number 22591456) (MAEDA, Minoru; KIKUCHI, Yu; Maurice E Jenkins; WATANABE, Motofumi; MAYEDA, Mayumi; and UCHIDA, Shin'ichi); and Scientific Research Grant awarded in fiscal 2013 (Basic Research (C) topic number 25460839).

\section{Results and Discussion}

\subsection{Education and School Library of Future}

The subject we addressed first was the nature of future education. We began our research using a theme that we called "defining next generation abilities," seeking to identify differences from our former/current approach to education. With the input of many people, including teachers, corporate citizens, and members of the local administration, we exchanged opinions regarding the future of education, arguing from many different points of view. As a result, it became clear that the core of education in the future and the educational role of the school library have many points in common. The fact that future reforms to accommodate digital education will likely involve a rejection of the past is concerning to many. In fact, many of those associated with paper media have a notable history of fearing digital media. For example, as the popularity of digital books increased and use of the Internet spread, it was feared that paper media would disappear completely. Renewed fear of digital media has been felt with the appearance of nearly every new digital development. It is not surprising, then, that there is fear of digital education, not only in school libraries but among teachers who are highly skilled in education.

In some sense, one should probably be cautious when using the word "digital" to identify or differentiate a new product. In fact, as digital technology spreads and becomes a part of our everyday life, digitized products will become commodities, and the special label of "digital" will likely no longer be used. Already, computerized components are being built into more and more of the products we use in our daily lives, from refrigerators, to washing machines, cars, and credit cards. In most cases, people are not actually conscious of the existence of these components, and the word "digital" is rarely used to promote the products that contain them. Thus, the negative response that the word "digital" can prompt is avoided or minimized.

It is perhaps useful to consider what, if any, elements of "old" education are to be replaced by the new digital education. To date, digital education has not denied, replaced or rejected education that uses paper media. There is no doubt, however, that education in Japan is in need of improvement, particularly with respect to its traditional teaching method of one-way teacher-to-student learning. It is now expected that children be involved in active learning. In this regard, connecting school to the student's life outside school is considered important. Education should not be simply memorising bits of knowledge, but it should provide a foundation for acquiring and utilising knowledge in life. Children best learn in school on the basis of questions discovered in their own lives. An education that multiplies the ideas of every 
child and conveys the wisdom accumulated in society is what is required. The massive 2012 earthquake in northern Japan that caused a huge tsunami and severe damage to a nuclear power plant had no comparable predecessor. It seemed impossible, but conditions and knowledge change. A Japanese future radically affected by increased longevity and an extremely low birth rate was never anticipated, but now Japan looks ahead to a society in which the number of young men will decrease dramatically, with implications that cannot be fully understood. Training our children to think critically and instilling in them the ability to survive in a changing society is essential.

It can be argued that it is precisely this kind of ability that the school library in Japan has helped develop for over 70 years. To those who view education as a one-way process, from teacher to student, and who believe memory ability is of primary importance, such education may seem new. However, for the school library community, this "new" thinking is actually at the core of the educational experience that school libraries have offered for many years. Thus, the school library community should have confidence rather than fear as digital education becomes a reality. The school library community has always had a comprehensive concept of educational contents and should be completely comfortable applying its experience with paper media to digital teaching materials. In the final analysis, it is not important whether teaching materials are paper or digital. Matters of physical media and their placement, such as the collection, arrangement, and storage of paper media have always been important in public libraries. In school libraries, one has had to pay attention not only to media form, but also to contents. In today's Cloud environment, media form and information contents have been separated. To improve the quality of education for the next generation will require applying the traditional experience of school libraries to an educational world in which digital teaching-materials will become increasingly available. This necessity became clear in our research.

\subsection{Evaluation of Digital Teaching Materials}

In order to improve educational quality, the evaluation function that school libraries have traditionally used can be a valuable tool. School libraries have, over many years, decided what books to purchase. Their collections have been assembled by their purchase of books suitable

for the school. They have played a key role in fostering a high quality educational environment by choosing books wisely and promoting active learning on the part of the students. In the school library, students actively choose their books, with the advice of teachers and librarians. In providing this advice, teachers and librarians are implicitly evaluating books. In many cases, students will refer to a recommended book list compiled under the authority of the school library conference, where teachers and librarians have collectively evaluated books. Thus, school library books are evaluated in a variety of ways. Given these facts, it seems most reasonable that the experience of book evaluation by school libraries can be beneficially applied to digital teaching materials. 
On this basis, we proceeded to create appropriate evaluation criteria. We gathered various digital contents, which included applications for tablet personal computers, websites, images, and various types of databases. We then created evaluation criteria, referencing the selection of a recommended book but also recognizing that the basic character of digital materials differs greatly from books. For example, in the case of applications used for a tablet computer, versions are updated frequently. Of course, revised editions of books may also be printed. However, in the case of an application, creators tend to release revised editions far more frequently and the function can change significantly. For this reason, even if an application is highly rated at a specific time, the evaluation will likely be valid for only a short term. In addition, unlike in the case of books, the entire contents of an application may not be available for evaluation. For example, for some applications, unless the rate of correct answers to a set of questions is high, the associated learning program remains locked. A global image of the application becomes clear only after the user appropriately answers all the questions. Furthermore, unlike books, an application operates interactively. In the case of books, what appears to the reader does not change according to the reader's reaction. Even if an evaluator assesses an application and limits the evaluation to a specific set of conditions, specifying the applicable range of the evaluation is difficult. Thus, digital contents tend to be difficult to view in their entirety, are updated frequently, can change substantially over time, and are interactive. For these reasons, judging whether specific digital contents are suitable for education is challenging. In most cases, a judgment of eligibility or approval comes with significant limitations.

In spite of these difficulties, the evaluation of digital contents is clearly not meaningless work. If one goes back to the starting point of the relationship between child and teacher and focuses on a specific situation, determining whether certain digital contents are useful is both important and feasible. As in the case of paper media, we should pay attention to the degree of match between the author's intention and the user's needs. For example, when judging whether to recommend a particular picture book, the evaluator judges not the specific worth of a single page but the whole flow of the story. For a pictorial book, although the flow of a story may not truly exist, the book is unified by the editorial policy. In the case of a newspaper, it is important to determine whether a specific article or report is useful for teaching. Although the newspaper is not specifically intended for school education, it can often contain stories that are valuable as teaching materials.

How should we evaluate digital teaching materials? According to our research, usefulness for teaching should be the highest consideration. A determination of eligibility or the rejection of certain teaching materials does not guarantee the overall quality of teaching materials. However, if the evaluation is limited to a specific learning unit and method of use, we can with 
confidence guarantee the effectiveness of learning activities. By accumulating individual practical use evaluations, we can establish the worth of digital teaching materials. In summary, then, we found that, for digital materials, the viewpoint of practical use in teaching is the foundation of proper evaluation.

\subsection{Examples of English and Health Education Applications}

To illustrate our approach, we use English language education as an example. English is taught as a foreign language in Japanese schools. In Japan, English is not a language for daily use, which means that students need to accumulate authentic input in addition to the input provided in classrooms in order to fully develop their English ability. In such a situation, digital contents offered by school libraries can be a valuable student resource. One important difference between digital contents and books is the availability of sound. Digital contents that offer sound provide students the opportunity to hear authentic input and should be highly evaluated. Students should also be encouraged to understand foreign cultures by studying English. In this regard, digital contents that report current events in foreign countries can be very useful. Students in Japan are becoming used to reading the news in abbreviated form on their smartphones and prefer accessing the latest information online rather than reading through a newspaper that often contains less-than-current news. Digital contents have the advantage of speed of information transmission. If current information about a foreign country is composed in simple English, students can develop their English skills at the same time they are expanding their knowledge of other cultures. For all these reasons, digital contents that cultivate students' cross-cultural understanding will be favorably evaluated.

Health education also provides a useful example. In Japan, school health education involves a complex combination of health and physical education. However, little time is devoted to discussing health issues. For example, while cautions regarding the health risks of tobacco or measures to reduce the risk of injury in physical activities are taught, there are few opportunities for a child to learn about the prevention and management of illness. In the budget of the Japanese government, medical expenses account for nearly 370 billion dollars annually. However, while reduction of medical expenses is currently a big subject in Japan, the medical education of children appears not to be a priority, and little time is devoted to teaching health. Given this condition, learning activities outside of school hours are expected. This provides school libraries a perfect opportunity to use digital teaching materials effectively. These days, informed consent and a second opinion are becoming a routine part of medical treatment. In order to achieve informed consent, it is important that patients learn as much as possible about their illness. To facilitate this, a patient-oriented library has been installed in many hospitals. The collection of books in such libraries can even function as a second opinion. Even in public libraries, a health information corner has become common. Following these developments, it 
seems highly appropriate to enrich the health information available in school libraries.

Importantly, school libraries can take advantage of their experience with books to evaluate relevant digital contents. Unfortunately, however, there are currently only a few health-related learning applications for a tablet computer or smart phone, and, in many cases, although there is the appearance of teaching health, the actual application is a mere game. An adult-oriented health guide is difficult for a child. In the future, it is likely that more health-related applications will be proposed and school libraries need to be in a position to properly evaluate their potential for teaching.

\section{Conclusion}

In digital education, the school library has an important role to play in the evaluation of digital contents. Evaluation does not necessarily determine the overall success or failure of contents, but it should be able to guarantee their effectiveness in learning activities that are limited to a specific learning unit and method of use. Accumulating examples of the use of digital contents in schools is important. The school library community can be an effective agent for the collection of useful evaluation examples.

\section{References}

東京学芸大学 デジ読評価プロジェクト(2016).『リーフレット』『授業づくりのための教育 コンテンツ集』「デジタル教材評価基準」Retrieved May 23, 2016, from https://sites.google.com/site/dejidoku/

文部科学省(2011).「OECD 生徒の学習到達度調査（PISA2009）デジタル読解力調査の結果に ついて」Retrieved May 23, 2016, from

http://www.mext.go.jp/b_menu/houdou/23/06/1307642.htm

\section{Biographical note}

Minoru MAEDA has worked as an Associate Professor at Tokyo Gakugei University in Japan since 2004. His main research topic is school libraries.

Masato FUJITA has worked as an English teacher at Saitama Prefectural Iruma Koyo High School in Japan since 2011. He has been a graduate student of Tokyo Gakugei University since 2015, majoring in English education. His main research topic is the role of school libraries in English education. 